\title{
Pecularities of Water Supply of Gas Wells in Massive Type Oil Reservoirs
}

\author{
Makhmudov N. N. ${ }^{1}$, Agzamov A. Kh. ${ }^{1}$, Ermatov N. Kh ${ }^{1} \&$ TurdiyevSh.Sh. ${ }^{1}$ \\ ${ }^{1}$ Karshi engineering-economics institute, Uzbekistan \\ Correspondence: Makhmudov N. N., Karshi engineering-economics institute, Uzbekistan. E-mail: \\ makhmudov.nazirila@bk.ru
}

Received: March 1, 2019

Accepted: April 1, 2019 Online Published: May 23, 2019

doi:10.5539/eer.v9n1p18

URL: https://doi.org/10.5539/eer.v9n1p18

\begin{abstract}
This article describes some problems on water supply of gas wells and reliable forecasting of watering gas outlets. Moreover, many ways of solving the issues have been recommended with scientific provident.
\end{abstract}

Keywords: watering, hydrodynamic, production, regression, gas wells, layer-by-layer, drafting, strata, sub gas, mechanism, carbonate, sediments, well production, simulators, limestone

\section{Introduction}

A reliable forecast of the watering of gas outlets of subgas deposits is one of the problems in the development of oil and gas fields. There are many geological and technological reasons for the premature watering of the production of wells of sub gas deposits: a breakthrough of bottom water, poor quality cement, large depression, layer-by-layer heterogeneity of the reservoir, etc.

The issue of the reliability of estimating the watering of wells at all stages of the development of subgas deposits is a complex task. Ways to solve the problem may be different: hydrodynamic models; multivariate regression analyzes and empirical methods.

Nowadays, to solve this issue, when drafting design documents for the development of oil and gas fields in Uzbekistan, Petrol's geological modeling and Schlumberger hydrodynamic simulators Eclipse 100 are widely used.

Their use makes it possible us to construct geological models of productive formations and complex hydrodynamic models that are sufficiently adequate to the actual conditions. They describe the mechanism of the filtration process of reservoir and working fluids injected into the formation. Obviously, this method is characterized by a high degree of theoretical substantiation of the mechanism of oil recovery and eliminates the error due to the human factor, due to the use of software and computer systems. However, design experience at the fields in Uzbekistan shows that this path, on the one hand, is very laborious, and on the other hand, there is not always reliable information about the properties of the productive strata.

In recent years, in Western Uzbekistan, a number of massive, low-volume subgas deposits have been introduced into development, with a limited amount of initial geological field information. In this connection, at the design stage of such oil deposits, there is no possibility of using hydrodynamic methods for calculating technological development indicators. In such cases, in order to substantiate one or another indicator of a development system, one has to resort to the results of generalizing the experience in developing fields in a given region that are in a late stage of operation.

It should be mentioned that with the entry of many fields in various oil-producing regions of the world into the late stage of development, systematic studies are being conducted to study the degree of influence of natural and technological indicators on the oil recovery factor (ORF) using mathematical statistics methods, especially using the regression analysis.

The aims of thisresearch is to establish the general laws of ORF, allowing to quantify and compare, as well as to predict the value of recoverable oil in different geological and physical conditions of deposits and development systems. A lot of material has been accumulated on deposits that are in the late and final stages of development, the results of summarizing the actual data on these deposits are of particular value for studying the influence of various technological solutions on the efficiency of implemented development systems. 
One of the main advantages of statistical models derived from multivariate regression analysis is that they allow us to establish not only the qualitative but also the quantitative influence of a particular indicator on the process, while the influence of other factors. This is one of the main reasons for the preferential use of statistical models for assessing the influence of geological and technological factors on the oil recovery factor in various geological and physical conditions of deposits, and not single-factor relationships.

Consider some of the tasks of well production watering based on the generalization of geological field materials from long-term gas and oil fields located in the Bukhara-Khiva oil and gas region of Uzbekistan, where the main productive horizons are confined to the Upper Jurassic carbonate sediments represented by limestones.

Analysis of the dynamics of the average water cut of wells constructed depending on the development period (Figure. 1), the depletion of recoverable reserves (Figure. 2) and the current oil recovery factor (Figure. 3) show that they differ significantly among themselves in the analyzed objects. In this regard, consider

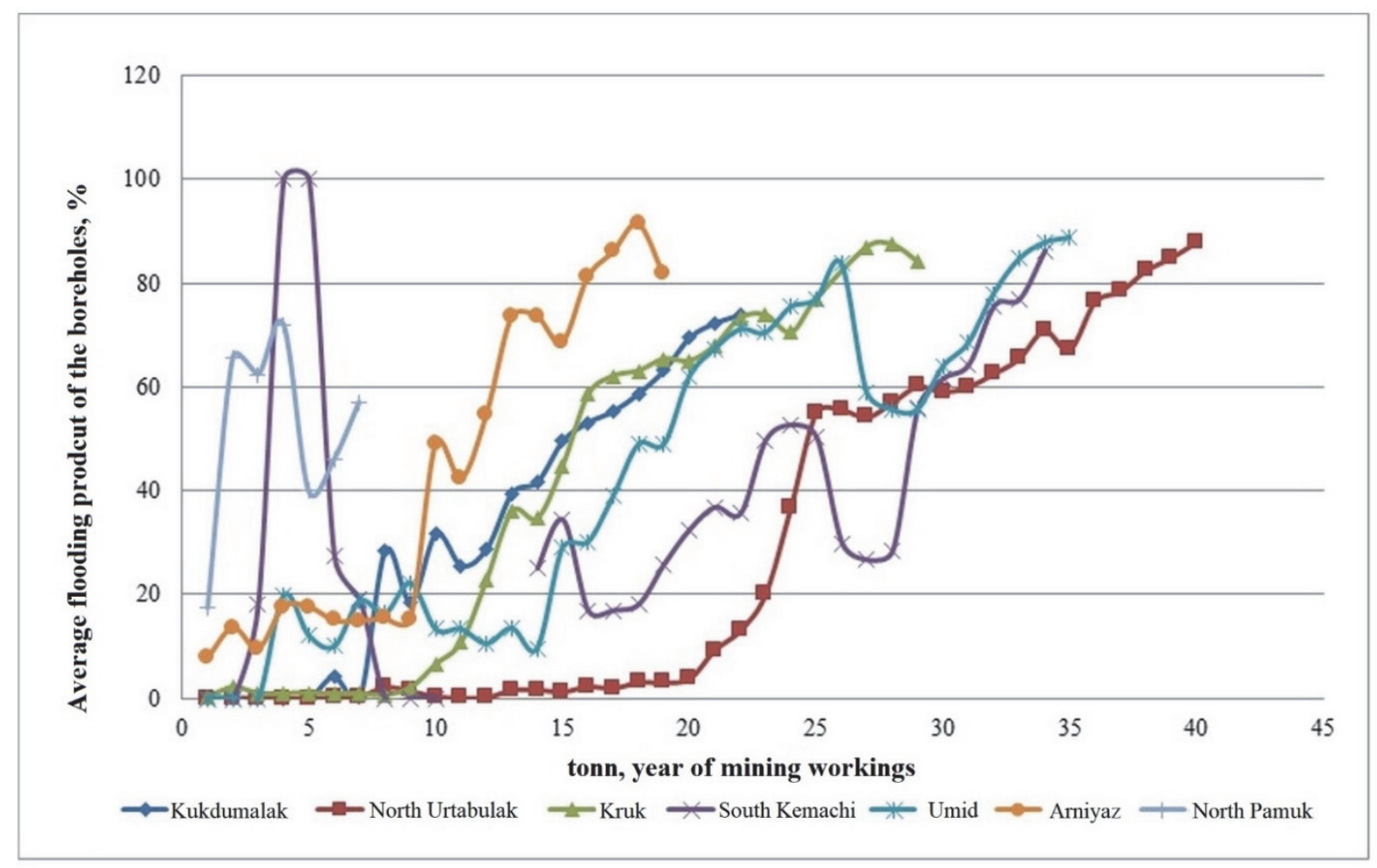

Figure 1. Dynamics of the average water-cut of wells from the development period 


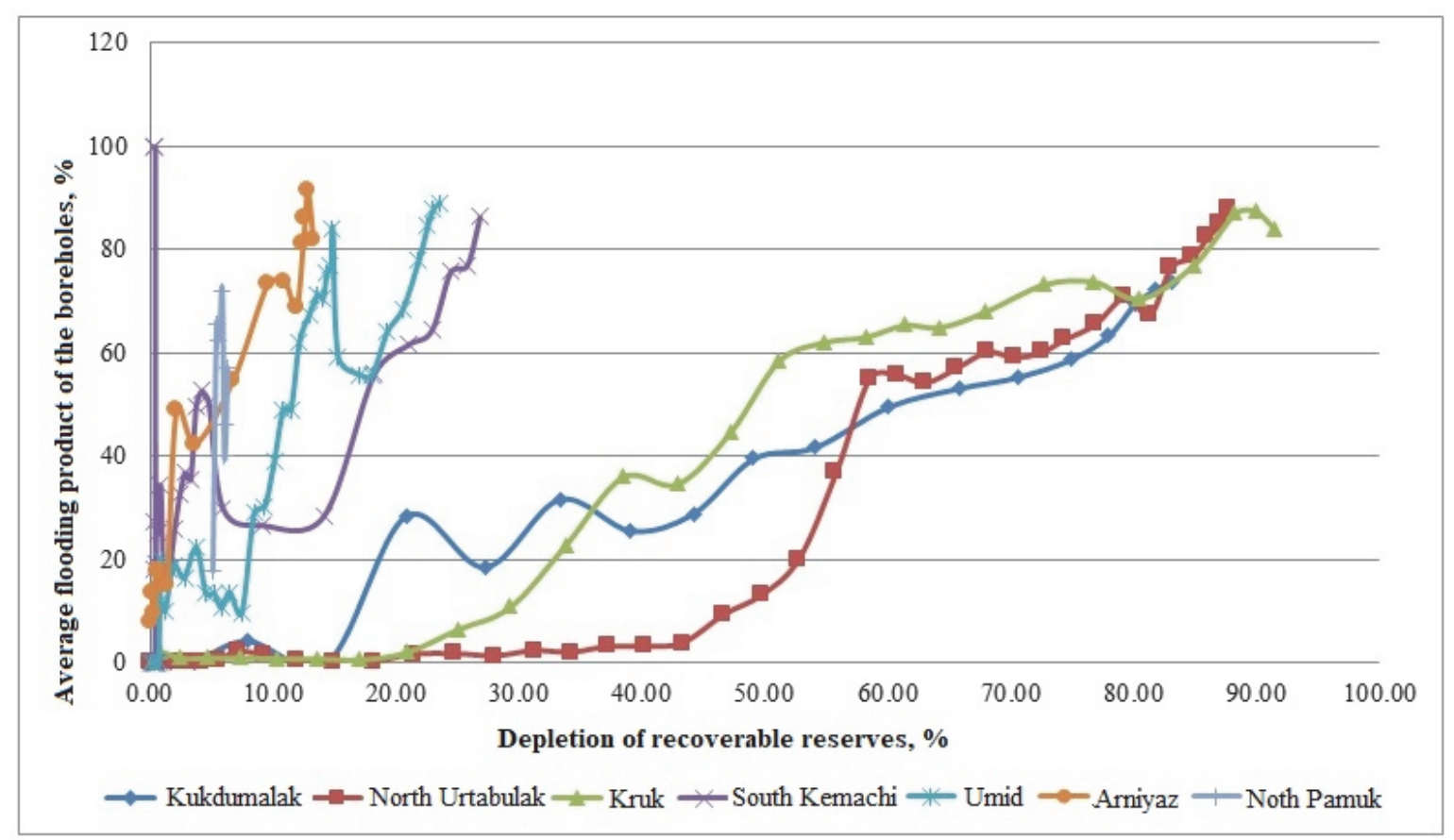

Figure 2. Dynamics of average water-cut of well production due to depletion of recoverable reserves

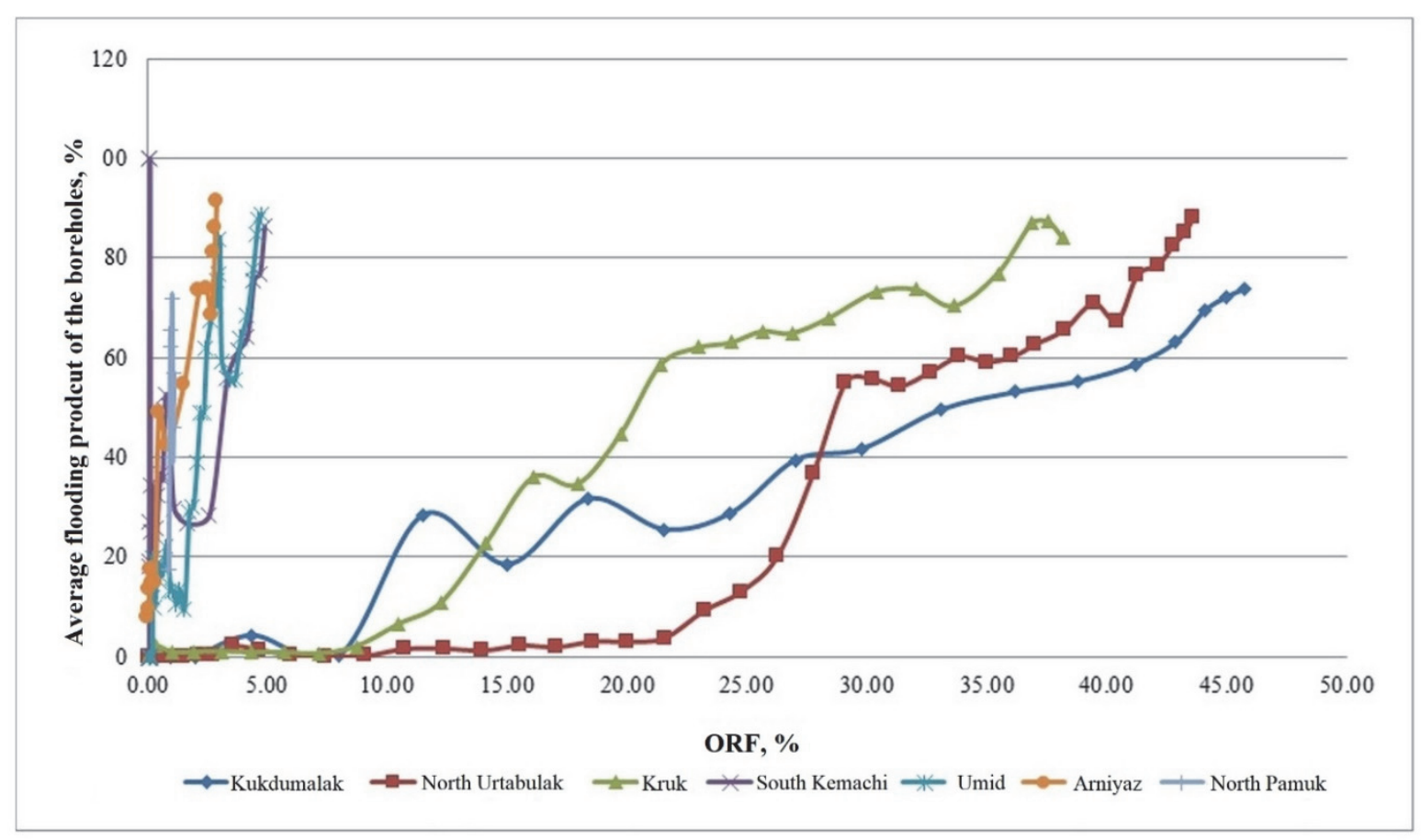

Figure 3. Dynamics of average water cut of wells from the current oil recovery ratiothe reasons for their differences with the use of multivariate correlation analysis

The experience of using the statistical models proposed so far shows that relatively reliable results are obtained when using them for conditions similar to those for which they were obtained [1,2].

To assess the statistical relationship using the correlation coefficient, which calculated by the formula: 


$$
r_{x y}=\frac{1}{(N-1) \cdot G_{x} \cdot G_{y}} \sum_{i=1}^{N}\left(x_{i}-\bar{x}\right)\left(y_{i}-\bar{y}\right)
$$

where $r_{x y}$-the correlation coefficient between the process indicators and one of the factors; $\bar{x}, \bar{y}$-mathematical expectations; $G_{x}, G_{y}$-dispersions calculated by formulas

$$
G_{x}^{2}=\frac{1}{(N-1)} \sum_{i=1}^{N}\left(x_{i}-\bar{x}\right)^{2} ; G_{x}^{2}=\frac{1}{(N-1)} \sum_{i=1}^{N}\left(y_{i}-\bar{y}\right)^{2}
$$

The reliability of the correlation coefficient is estimated by the criterion of reliability

$$
O_{r}=\frac{\left|r_{x y}\right|}{\sqrt{N}}
$$

where the standard deviation of the correlation coefficient

$$
G_{r}=\frac{1-r_{x y}^{2}}{\sqrt{N}}
$$

When criteria $\mathrm{Gr}>2,6$ with a probability of 0.95 , it is possible to assume the possibility of the existence of a linear correlation connection between the analyzed parameters. Correlation coefficients allow us to estimate the measure of the linear statistical relationship between indicators and factors, as well as between the factors themselves. The results of the correlation analysis are the source material for constructing empirical formulas, called equations in statistics.

The linear regression equation is

$$
y=\mathrm{a}_{0}+a_{1} x_{1}+a_{2} x_{2}+a_{3} x_{3}+\ldots+a_{n} x_{n},
$$

where $_{0}, a_{1}, a_{2}, a_{3} \ldots \ldots a_{n}$ - regression equation coefficient.

As a result of the calculations, a correlation matrix was constructed (Table 1) and an equation

\begin{tabular}{|c|c|c|c|c|c|c|c|}
\hline \multirow{2}{*}{$\begin{array}{l}\text { Factors and } \\
\text { indicator }\end{array}$} & \multicolumn{5}{|c|}{ Correlation coefficient } & \multirow{2}{*}{$\begin{array}{l}\text { Average } \\
\text { values }\end{array}$} & \multirow{2}{*}{$\begin{array}{l}\text { Standard } \\
\text { deviation }\end{array}$} \\
\hline & ORF & $\mathrm{h}_{\text {н }}$ & $\mathrm{V}_{\mathrm{H}} / \mathrm{V}_{3}$ & $\mathrm{~S}$ & B & & \\
\hline ORF & 1 & 0,737 & 0,113 & $-0,547$ & 0,141 & 0,1552 & 0,1505 \\
\hline $\mathrm{h}_{\mathrm{H}}$ & 0,737 & 1 & 0 & 0 & 0 & 26,6607 & 15,7046 \\
\hline $\mathrm{V}_{\mathrm{H}} / \mathrm{V}_{3}$ & 0,113 & 0 & 1 & 0 & 0 & 0,4740 & 0,2759 \\
\hline S & $-0,547$ & 0 & 0 & 1 & 0 & 24,3219 & 22,0945 \\
\hline B & 0,141 & 0 & 0 & 0 & 1 & 42,7725 & 31,5353 \\
\hline
\end{tabular}
was obtained in the form:

$$
\mathrm{ORF}=0,0071 \cdot \mathrm{h}_{\mathrm{H}}+0,0616 \mathrm{~V}_{\mathrm{H}} / \mathrm{V}_{3}-0,0037 \cdot \mathrm{S}+0,0070 \cdot \mathrm{B}
$$

Table 1. Correlation Matrix

As can be seen from the results of calculations at comparable values of oil viscosity and reservoir permeability, the effective oil saturated formation has the greatest influence on the process of extracting oil from subgas gas deposits (hH) and the grid density of the wells $(\mathrm{S})$, the ratio of oil-saturated volume to the total volume of the reservoir and the water-cut of the well production have a relatively lesser effect.

It should be noted that the obtained equation (6) does not replace the existing methods of substantiation of ORC for different values of $\mathrm{B}$, depending опhн, $\mathrm{VH} / \mathrm{V} 3$ и $\mathrm{S}$, but it can be used to conduct an express analysis of the development of sub gas oil deposits of the massive type.

\section{References}

Abdulmanov, S. Kh., Sagitov, D. K., Saifullin, I. R., \& Astakhova, A. N. (2012). Frequency analysis of the interaction of neighboring wells to change the volume of injection and the water content of products on the history of operation. Oilfield business, 11, 20-24. 
Bagautdinov, R. A., \& Bagautdinov, A. K. (2006). Analysis of the impact of adjusting the design location of wells on the development efficiency of the BV8 object of the Soviet oil field. Oil industry, 8, 54-57.

Ibragimov, L. Kh., Mishchenko, I. T., \& Cheloyants, D. K. (2000). Intensification of oil production. Moscow: Science, 414.

Irmatov, E. K., Jalilov, M. M., Khuzhayerov, B. Kh., \& Agzamov, A. Kh. (2016). The use of probabilistic statistical methods in the analysis and design of the development of oil and gas fields. T .: Fan WA Technology, 304.

Kan, A. G. (2010). Change of sources of irrigation wells in the development process. Geology, geophysics and development of oil and gas fields, 4, 84-87.

Kocherbitova, V. M. (1968). On the nature and conditions of irrigation of production wells in the areas of the Romashkinskoye field. Oil industry, 12, 38-42.

Makhmudov, N. N., Boimuradov, S. N., Agzamova, S. A., \& Karshiev, A. Kh. (2011). The degree of influence of geological field factors on the current and final oil recovery of layers. Uzbek Journal, Oil and Gas, 4, 4-7.

Makhmudov, N. N., Muhammadiev, Kh. M., \& Bobomurodov U. Z. (2018). Analysis of the depletion of oil reserves of the Kruk field.Uzbek journal, Oil and gas, 2, 18-22.

Mirzadzhanzade, A. Kh., \& Stepanova, G. S. (1977). Mathematical theory of experiment in oil and gas production. Nedra, 288.

Muminov, I. M., \& Agzamov, A. Kh. (1997). Relocation of water-oil contact at the North Urtabulak field in the process of development. Uzbek Journal, Oil and Gas, 3, 23-26.

Nasibullin, M. G., Zakirov, R. R., \& Kruglov, M. P. et al. (2005). Analysis of the dynamics and nature of premature watering of borehole products of carbonate reservoirs. Oilfield business, 3, 15-21.

Nazarov, U. S., Irmatov, I. K., Agzamov, A. Kh., \& Posevich, A. G. (2004). Experience in designing the development of subgas gas deposits in Uzbekistan. Uzbek Journal, Oil and Gas, 2, 27-30.

Taziev, M. Z., Kayumov, M. Sh., \& Khisamutdinov, A. I. et al. (2003). Comprehensive accounting of the energy of the reservoir and the current state of its development when selecting wells for stimulating oil production. Oilfield business, 7, 33-36.

Vladimirov, I. V., Kazakova, T. G., \& Vafin, R. N. et al. (2004). On a possible mechanism for irrigation of production wells exploiting deposits of viscous and highly viscous oil. Oilfield business, 6, 73-77.

Zemtsov, Yu. V., \& Ustyugov, A. S. (2016). Multifactor analysis of the effectiveness of restricting water inflows in various geological and physical conditions of wells and formations. Oilfield business, 5, 20-25.

\section{Copyrights}

Copyright for this article is retained by the author(s), with first publication rights granted to the journal.

This is an open-access article distributed under the terms and conditions of the Creative Commons Attribution license (http://creativecommons.org/licenses/by/4.0/). 